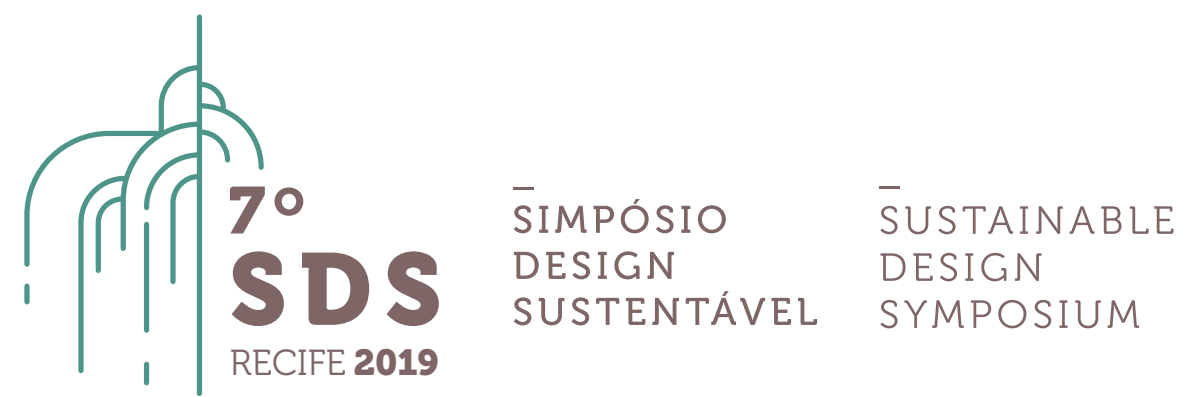

\title{
Análise dos copos descartáveis após 100 anos de uso
}

\author{
Autor Claudia Vanessa Oliveira Couto1, Alfredo Jefferson de Oliveira 2 \\ 1Pontifícia Universidade Católica do Rio de Janeiro, Artes e Design, vancouto@gmail.com \\ 1 Pontifícia Universidade Católica do Rio de Janeiro, Artes e Design, alfredo@puc-rio.br
}

\begin{abstract}
Resumo Este artigo apresenta reflexões em torno do problema do lixo plástico gerado em grande parte pelo uso de copos descartáveis. Eles surgiram na década de 1910 e evoluiram de uma simples solução de saúde para um objeto de conveniência cotidiano. Porém esta conveniência está causando uma poluição plástica sem precedentes. $O$ artigo propõe analisar em que contexto os copos descartáveis surgiram e se estabeleceram. Conclui que o plástico possibilita ótimas soluções para a nosso bem viver, mas o seu uso deve ser restrito $e$ acompanhado. Para lidar com este problema precisamos desenvolver sistemas mais inclusivos, estimulando a participação da sociedade, governo, iniciativa privada e terceiro setor, afim de projetar ações mais eficazes no combate à poluição.
\end{abstract}

Palavras-chave. Copo descartável; Sustentabilidade; Poluição plástica; Reciclagem; Sociedade.

\begin{abstract}
This article presents reflections on the problem of plastic waste generated in large part by the use of disposable cups. They emerged in the 1910s and evolved from a simple health solution to an everyday object of convenience. But this convenience is causing unprecedented plastic pollution. It is proposed to analyze in what context the disposable cups have emerged, have settled, and because we live together and need the disposable ones. It Concludes that plastic makes possible great solutions for our well live, but its use must be restricted and that to deal with the problem of plastic pollution we need to develop more inclusive systems, stimulating the participation of society, government, private sector and the third sector in order to design increasingly effective actions in the fight against pollution.
\end{abstract}

Keywords. Disposable cup; Sustainability; Plastic pollution; Recycling; Society.

\section{Introdução}

Passamos a não respeitar os ciclos da natureza, fazemos uso dos recursos naturais e em 
troca produzimos lixo. Os potenciais danos à natureza decorrentes de processos produtivos industriais deixaram de ser os únicos a serem questionados, os impactos resultantes de hábitos de consumo cotidiano precisam ser repensados. A busca por produtos e serviços de menor impacto sobre a qualidade do meio ambiente tornou-se urgente. A poluição plástica cresceu e estabeleceu uma realidade com prognóstico de difícil reversão, causando a contaminação do solo, da água, dos oceanos, matando animais com macro, micro e nanoplásticos.

Desde 2000, o mundo já produziu a mesma quantidade de plástico que em todos os anos anteriores somados, a produção de plástico virgem aumentou 200 vezes desde 1950 e cresce a um índice de $4 \%$ ao ano desde 2000. Eliminar gradualmente o plástico descartável, aquele com vida útil de um ano, tem o potencial de diminuir a demanda por plástico em até $40 \%$ até 2030 . Quase metade de todo plástico produzido vira lixo em menos de três anos segundo a WWF(2019) ${ }^{1}$. A inabilidade mundial de gerir os resíduos plásticos faz com que um terço de todo o plástico, equivalente a 100 milhões de toneladas métricas de resíduos, se transforme em poluição terrestre ou marítima. ${ }^{2}$

A superpopulação e o rápido desenvolvimento de indústrias e estilo de vida levaram a aumento do consumo de recursos naturais e redução dos mesmos. O aumento de resíduos que foram gerado pelas industrias e as atividades humanas precisam ser gerenciadas. $O$ processo de manufatura sustentável e o gerenciamento de resíduos sólidos são usados para conservar recursos naturais valiosos, impedindo a emissão desnecessária de gás e protegendo as saúde. $O$ uso de plástico em utensílios de mesa descartáveis devem ser repensados. A reciclagem enfrenta muitos obstáculos para que aconteça plenamente a ponto de criar um equilíbrio entre produção e descarte.

Este artigo trata da análise de como e porque o uso de copos descartáveis começaram a ser incorporados pela sociedade e quais os desdobramentos deste uso. $\mathrm{O}$ atual sistema de uso de descartáveis precisa mudar, entender porque surgiram e se estabeleceram nos faz compreender que não poderemos bani-los do nosso convívio e sim adaptá-los a uma nova realidade. Além de novos insumos usados na produção dos utensílios de mesa descartáveis, ainda precisamos lidar com as opções existentes. A reciclagem que parecia ser uma solução acessível se mostrou de difícil execução. A separação, transporte e a reincorporação de materiais reciclados ainda são um desafio. $O$ método utilizado foi a pesquisa bibliográfica onde foram coletados dados de pesquisas recentes sobre a poluição plástica, passando a uma breve história dos copos descartáveis, reciclagem e caminhos a serem percorridos. A fim de identificar possíveis propostas de sucesso para lidar com o resíduo gerado pelo uso de copos descartáveis, foi citado um caso que está em andamento. Se trata de uma campanha que inclui a participação da sociedade, terceiro setor, governo, empresas de reciclagem e grandes varejistas.

\section{Breve História dos copos descartáveis}

O primeiro copo descartável documentado era de papel e foi inventado na China no século II aC. Eles eram usados para servir chá e eram chamados de chih pei. ${ }^{3}$ Os copos descartáveis, como conhecemos hoje, foram criados no inicio do século XX por Lawrence Luellen, um advogado americano de Boston, influenciado pela descoberta científica onde confirmava que o uso de copos compartilhados disseminavam doenças como cólera e difteria. Compartilhar copos era uma prática bem comum principalmente nas estações ferroviárias, eram usados barris de água onde os

\footnotetext{
${ }^{1}$ Estes dados foram fornecidos pelo relatório "Solucionar a Poluição Plástica: Transparência e Responsabilização" realizado pela Dalberg Advisors para a WWF (Fundo Mundial para a Natureza), Gland, Suíça.

${ }^{2}$ Mais infomações disponível em: $<$ https://onlinelibrary.wiley.com/doi/abs/10.1111/gcb.14020>

${ }^{3}$ Science and Civilization in China: Paper and Printing
} 
passageiros mergulhavam os copos compartilhados. Em 1910 Lawrence Luellen e seu cunhado Hugh Moore, se mudaram para Nova York e desenvolveram uma máquina que produzia copos estéreis, os Health Kups. Com esta invenção os copos, feitos de papel com uma fina camada de cera, ficavam num dispenser e eram de uso único, evitando assim a contaminação.

Figura 1 - Uso de copos compartilhados em fonte pública.

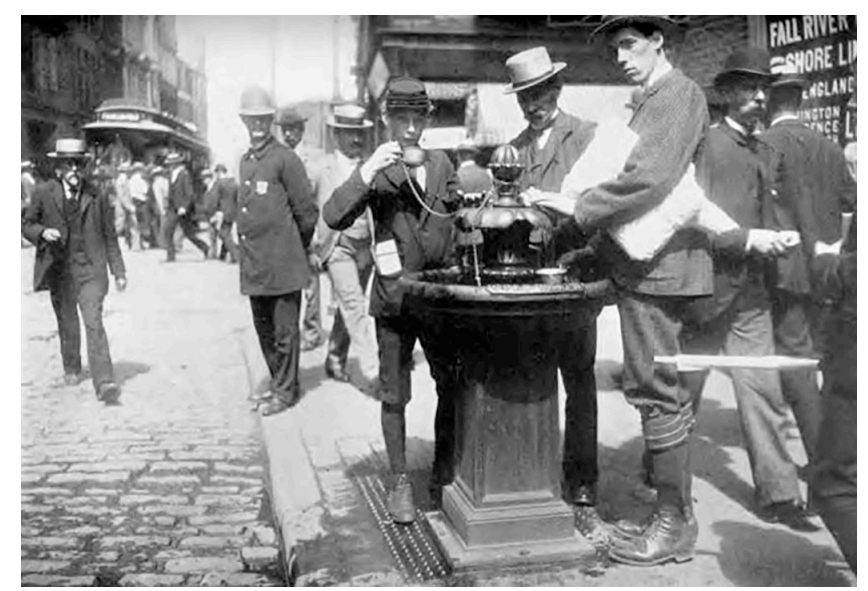

Fonte: Kempe (2006)

Os copos descartáveis foram gradualmente sendo aceitos pela população, o convívio com muitos casos de doenças infectocontagiosas causando muitas mortes e a publicação do estudo, cujo o título era Death in School Drinking Cups, realizado por Alvin Davison, professor de biologia no Lafayette College, publicado na Technical World Magazine em agosto de 1908 e reimpresso e distribuído pelo Conselho Estadual de Saúde de Massachusetts em 1909, contribuíram com o entendimento da necessidade do uso dos copos descartáveis em locais públicos. Passaram então a ser usados nas estações de trem, nos hospitais evitando contaminação cruzada, nas escolas, nas indústrias e nas repartições públicas.

Em 1918 a Gripe Espanhola matou mais pessoas do que a Primeira Guerra Mundial, de acordo com os registros do arquivo Nacional dos Estados Unidos, a maior pandemia mundial, atingiu $25 \%$ da população dos Estados Unidos. E a difteria havia causado, só nos Estados Unidos, de 13000 a 15000 mortes por ano, na década de 1920, conforme dados do CDC. ${ }^{4}$ O que serviu de grande estímulo para o desenvolvimento da linha de copos descartáveis de uso doméstico em 1921.

Os copos descartáveis foram imprescindíveis na Segunda Guerra Mundial, com as forças armadas americanas no exterior, os copos de papel descartáveis foram fornecidos aos milhões às linhas de frente. Atingiram o seu objetivo completamente. Em alguns lugares como hospitais e lanchonetes, o seu uso se tornou obrigatório. Ele exerce a função, para qual foi criado, até hoje e continua a evitar doenças.

Somado à higiene veio a praticidade, e essas características tiveram muita identificação com a cultura do fast food. Os americanos após a segunda guerra viveram um momento de euforia e incertezas que os levaram a um comportamento opulente e imediatista. A sociedade americana foi invadida pelo uso de práticas de venda pautadas nas obsolescências de função, qualidade e desejabilidade, levando à uma mudança de hábito, à deterioração dos princípios sociais instituída por um sistema capitalista com uma produtividade industrial agressiva.

\footnotetext{
${ }^{4}$ CDC - Centros de Controle e Prevenção de Doenças dos Estados Unidos. Maiores informações em: https://www.cdc.gov/vaccines/pubs/pinkbook/index.html ou https://pt.wikipedia.org/wiki/Difteria
} 
Manipulando o consumidor e o levando a um consumo excessivo e gerando uma devastação dos recursos naturais e uma consequente produção de lixo. Os descartáveis retrataram muito bem o momento e o que estaria por vir, reforçando a afirmativa de Juez (2002) :

Um objeto, fruto de um projeto de design, pode ser a reprodução de um antecedente, exclusivo ou de uso comum, exemplar único ou numeroso; pode ter sido inspirado em algum tema ou na natureza; surgir da mente de seu criador e da comunidade a qual pertence. Em qualquer circunstancia, um objeto sempre será a expressão legítima de um modo de viver e ver o mundo do ser humano(JUEZ, 2002,p.13).

Na década de 1960 surge o primeiro copo derivado do petróleo e que poderia ser usado para bebidas quentes, o copo de espuma-isopor e logo depois foi substituído pelos copos de plástico que foram apresentados como os mais ecológicos, já que não poluíam o ar pelo pentano liberado na produção dos copos de espuma, e nem poluíam a água, como os copos de papel que na fabricação da época usavam produtos como cloro, dióxido de cloro e sulfetos que eram liberados na água na sua produção. Os copos de plásticos eram leves, higiênicos, podiam ser usados com bebidas quentes, duráveis, reutilizáveis e seguros. Esta alteração mudou completamente a sua trajetória. O plástico trouxe aos utensílios de mesa descartáveis duas sensações ambíguas: a necessidade e a repulsa.

A primeira patente de um copo de plástico foi emitida nos Estados Unidos no início da década de 1960, sua ideia era de um recipiente de plástico de paredes finas, mas o inventor não denominou como copo e permitiu que outros registrassem suas próprias invenção de copo de plástico descartável. Nesta mesma década o desequilíbrio sobre a geração de resíduos sólidos e produtos tóxicos derivados de meios de produção e descarte começa a ficar claro. Em oposição a estes movimentos hedonistas surgem os movimentos ambientais e a consciência da finitude dos recursos naturais. Porém o copo descartável ainda não era um problema ambiental, ele começou a causar algum incomodo quando o lixo foi aumentando e ficando cada vez mais visível. A união do crescimento do consumo em massa e aumento do uso de plásticos levou a quantidade de resíduos sólidos a aumentar sete vezes no final da década de 1960. Assim nasce a dinâmica descartáveis, lixo, poluição. Um leitor americano se manifestou dizendo:

\begin{abstract}
"Vamos parar por algum tempo com essa pesquisa e desenvolvimento! Estamos agora até o pescoço de progresso...Estamo-nos inundando com lixo. A ciência inventa lixo; a indústria o produz em massa; o comércio vende-o; a publicidade condiciona os nossos reflexos para procurarmos a grande caixa dele. Não há dúvida, somos todos lixeiros especializados - mas que vai ser de nós? Até onde avançamos? Somos homens da caverna orientados para o lixo?" ( PACKARD, 1960, p.58).
\end{abstract}

\title{
3 Reações à poluição
}

As manifestações de preocupação sobre o estado da natureza são antigas mas organizações mais consistentes aparecem no final da década de 1960 como, por exempo, o Clube de Roma ${ }^{5}$ que era formado por um grupo de pessoas ilustres que se reuniam para debater um vasto conjunto de assuntos relacionados a política, economia internacional e, sobretudo, ao meio ambiente e o desenvolvimento sustentável. Tornou-se muito conhecido a partir de 1972, ano da publicação do relatório intitulado Os limites do Crescimento ${ }^{6}$, e muitos outros, como a conferência das Nações Unidas sobre o Meio Ambiente Humano, também conhecida como a Conferência de Estocolmo, foi a primeira grande reunião de chefes de Estado organizada pelas Nações Unidas (ONU) para tratar das questões relacionadas à degradação do meio ambiente,

\footnotetext{
${ }^{5}$ The Limits to Growth - Limites do Crescimento (MEADOWS et al., 1972) Disponível em:

$<$ http://www.ipea.gov.br/portal/images/stories/PDFs/boletim_regional/081207_boletimregional1_cap3.pdf $>$. Acesso em: 20 maio 2019.

${ }^{6}$ The Limits to Growth. 1972. Mais informações disponível em: $<$ https://pt.wikipedia.org/wiki/Clube_de_Roma $>$. Acesso em: 20 maio 2019
} 
realizada entre os dias de 5 a 16 de junho de 1972 na capital da Suécia, Estocolmo.

Os movimentos ambientais e a multiplicação do lixo urbano estimularam criação de leis para organizar os resíduos sólidos, porém estas leis não foram suficientes para limitar o dano. Uma pesquisa publicada pelo fórum Econômico Mundial e da Fundação Ellen Mac Arthur, afirma que em 2050 haverá mais plástico nos oceanos do que espécies marinhas. O Brasil já é o quarto produtor de lixo plástico do mundo, ficando atrás apenas dos Estados Unidos, China e Índia, dados do estudo feito pelo Fundo Mundial para a Natureza. ${ }^{7}$

Atualmente leis mais robustas ligadas a questão dos descartáveis estão aparecendo, elas instituem a obrigatoriedade à substituição dos utensílios de mesa descartáveis de plástico por utensílios de mesa descartáveis com no mínimo de 50\% de material biodegradável. Na França, o Decreto $\mathrm{n}^{\circ}$ 2016-1170 de 30 de agosto de 2016, proíbe a venda de utensílios de mesa descartáveis de plástico a partir de 2020. Será permitido utensílios descartáveis com um mínimo de $50 \%$ de materiais orgânicos e biodegradáveis. No Rio de Janeiro foi proibido o uso de canudos de plástico, são permitidos apenas de papel ou material biodegradável. Na Alemanha, Áustria e Suíça os descartáveis são proibidos em eventos. Taiwan e Índia também estão criando leis para proibir os descartáveis que não sejam biodegradáveis.

A maioria das embalagens plásticas é usada apenas uma vez e 95\% de seu valor, estimado em US $\$ 80$ bilhões a US $\$ 120$ bilhões anuais, é perdido para a economia após o seu uso inicial. Além disso, gera externalidades negativas, degradação sistemas naturais e emissões de gases de efeito estufa, que foram avaliados conservadoramente pelo PNUMA ${ }^{8}$ em US $\$ 40$ bilhões. $^{9}$

\section{Reciclagem}

Após mais de 40 anos do lançamento do primeiro símbolo universal de reciclagem, que apenas $14 \%$ das embalagens de plástico são recolhidas para reciclagem globalmente. A cada ano, US $\$ 80$ bilhões - US $\$ 120$ bilhões de plástico é perdido para a economia. ${ }^{10}$

A durabilidade dos plásticos e seu potencial para diversas aplicações, incluindo o uso generalizado como itens descartáveis, foram antecipados, mas os problemas associados ao gerenciamento de resíduos e detritos plásticos não o foram. De fato, as previsões eram "quanto mais brilhante e mais limpo o mundo [seria] do que aquele que precedeu essa era plástica" (Yarsley e Couzens, 1945).

As empresas em todo o mundo enfrentam custos crescentes em materiais, energia e conformidade, juntamente com expectativas mais altas de clientes, investidores e comunidades locais, porque descartam recursos naturais valiosos como desperdício. ${ }^{11}$

Como recurso para reduzir as quantidades de resíduos plásticos que geramos eram usados os três Rs - reduzir, reutilizar e reciclar. Hopewell et al. (2009) descrevem os benefícios e limitações dessas estratégias. Eles mostram que, para ser eficaz, precisamos considerar os três Rs em combinação uns com os outros e juntos com um quarto "R", a recuperação de energia. Para Hopewell, Dvorak e Kosior (2009)também precisamos considerar um 5ㅇ "R", redesenho molecular, como uma estratégia emergente e potencialmente muito importante. Assim, os três Rs tornam-se cinco: "reduzir, reutilizar, reciclar, recuperar e redesenhar". No entanto, a recuperação de energia

\footnotetext{
${ }^{7}$ Fundo Mundial para a Natureza -WWF relatório realizado pela Dalberg Advisors para a WWF

${ }^{8}$ Programa das Nações Unidas para o Ambiente - voltado à promoção do desenvolvimento sustentável.

${ }^{9}$ World Economic Forum, Ellen MacArthur Foundation and McKinsey \& Company, The New Plastics Economy Rethinking the future of plastics (2016, http://www.ellenmacarthurfoundation. org/publications).

${ }^{10}$ World Economic Forum, Ellen MacArthur Foundation and McKinsey \& Company, The New Plastics Economy Rethinking the future of plastics (2016, http://www.ellenmacarthurfoundation. org/publications).

${ }^{11}$ Sustainable Solid Waste Recycling. Disponível em: http://dx.doi.org/10.5772/intechopen.70046
} 
não reduz a demanda por matéria-prima usada na produção de plástico, por isso é considerada menos eficiente em termos energéticos do que a recuperação de produtos via reciclagem (WRAP 2006; Defra 2007) ${ }^{12}$. Além disso, preocupações sobre emissões de incineradores (Katami et al. 2002) podem reduzir o apelo desta opção de eliminação de resíduos.

A mensagem de reciclagem é simples; tanto a indústria quanto a sociedade precisam considerar os itens em fim de vida, inclusive os plásticos, como matérias-primas, e não como resíduos. Atualmente, nosso consumo de combustíveis fósseis para produção de plástico é linear, do óleo ao lixo via plástico. É essencial adotar uma abordagem mais cíclica ao uso de material, mas alcançar esse objetivo é complexo (Hopewell et al. 2009).

\section{Evolução dos materiais usados nos copos descartáveis}

Além dos plásticos derivados do petróleo existem os plásticos biodegradáveis, que têm o potencial de resolver uma série de questões de gestão de resíduos. É possível incluir plásticos biodegradáveis em compostagem aeróbica ou por digestão anaeróbica com captura de metano para uso de energia. No entanto, os plásticos biodegradáveis também têm o potencial de complicar o gerenciamento de resíduos quando introduzidos sem atributos técnicos apropriados, sistemas de manuseio e educação do consumidor. Além disso, pode haver problemas na obtenção de biomassa suficiente para substituir uma grande proporção do consumo atual de polímeros (Soetaert \& Vandamme 2006). É necessário que os plásticos compostáveis e degradáveis sejam apropriadamente rotulados e usados de maneira a complementar, ao invés de comprometer os esquemas de gerenciamento de resíduos (Song et al. 2009).

Os biopolímeros são materiais com funcionalidade comparável aos plásticos convencionais e podem ser produzidos em escala industrial. Eles diferem dos polímeros convencionais, pois sua matéria-prima é de biomassa renovável, em vez de ser baseada em óleo. Podem ser polímeros naturais (por exemplo, celulose) ou polímeros sintéticos feitos a partir de monómeros de biomassa (por exemplo, PLA) ou polímeros sintéticos feitos a partir de monómeros sintéticos derivados de biomassa (por exemplo, polietileno derivado de bioetanol) (WRAP 2009). Eles são frequentemente descritos como polímeros renováveis, uma vez que a biomassa original, por exemplo, o milho cultivado na agricultura, pode ser reproduzida. A emissão de dióxido de carbono pode ser menor do que a dos polímeros convencionais, mas não é zero, uma vez que a produção agrícola e de pesticidas tem produção de dióxido de carbono (WRAP 2009).

Uma solução é reciclar o desperdício de alimentos em biopolímeros; ou ainda resíduos orgânicos industriais como caroço de abacate, casca de coco, bagaço da cana- de- açúcar. Song et al. (2009) mostram experimentalmente que a degradação de polímeros biodegradáveis, em oposição a compostáveis, pode ser muito lenta em compostores domésticos. A degradação destes polímeros em aterros também é provável que seja lenta e pode criar emissões indesejadas de metano. Assim, os benefícios dos biopolímeros só são percebidos se forem descartados em um sistema apropriado de gerenciamento de resíduos que use suas características biodegradáveis. Tipicamente, isto é conseguido através de compostagem industrial a $50^{\circ} \mathrm{C}$ durante cerca de 12 semanas para produzir composto como um produto útil.

Em 2009 (Song et al. 2009) afirmava que os biopolímeros eram mais caros que os polímeros convencionais e respondiam por menos de $1 \%$ da produção de plásticos. Este percentual vem aumentando, no Brasil, a CBPak Tecnologia ${ }^{13}$, uma empresa situada no Rio de Janeiro, que fabrica bandejas e copos compostáveis a partir de fécula de mandioca mantém seu

\footnotetext{
${ }^{12}$ Defra:Department of Environment food and Rural Affairs

${ }^{13}$ CBPAK- É uma empresa de tecnologiagenuinamente brasileira, focada na pesquisa, desenvolvimento, industrialização e comercialização de embalagens descartáveis produzidas a partir de material-prima de fonte renovável, a fécula da mandioca.
} 
crescimento desde de 2002. Além de uma produção com gastos hídricos menores que a produção de copos de plástico, tem melhorado o custo do seu produto chegando a valores bem próximo a dos copos de plástico. No México, a empresa Biofase, fundada em 2012, criou um bioplástico a partir do caroço de abacate, um resíduo da agroindustria que produz azeite, guacamole e molho, e que descartam mensalmente 30,7 mil toneladas de caroços de abacate. Estima-se que são desperdiçadas cerca de $\mathbf{3 0 0}$ mil toneladas de caroços de abacate e que a utilização deste volume para fabricação de bioplásticos poderia atender a aproximadamente $30 \%$ da demanda mundial desse produto. A Biofase cresceu $700 \%$ entre 2013 e $2014 .{ }^{14}$ Os seus produtos tem o mesmo custo dos utensílios descartáveis de plástico convencional. De acordo com dados da Associação Europeia de Bioplásticos, o mercado global de bioplásticos possui um valor de US\$ 4 bilhões.

Assim, embora os biopolímeros ofereçam algumas soluções de gerenciamento de resíduos, há limitações e consideráveis mal-entendidos entre o público em geral sobre sua aplicação (WRAP 2007). Para obter o máximo benefício de materiais degradáveis, biodegradáveis e compostáveis, é essencial identificar usos específicos que ofereçam vantagens claras, associar a rotulagem para indicar uso e descarte apropriado. Mas, se forem para compostagem ou para um biodigestor, 0 resultado é lixo zero. Apesar do crescimento do setor e de parecer ser o futuro dos utensílios de mesa descartáveis, ainda precisamos lidar com o lixo plástico, a produção de plásticos tem crescido continuamente por mais de um século. Em 2015, a produção global de plásticos atingiu 322 milhões de toneladas (PlasticsEurope, 2016).

\section{Caso}

Ações isoladas parecem incapazes de lidar com o problema do lixo plástico, ele faz parte de um impasse sistêmico de fluxos globais de materiais excessivamente grandes e complexos. É difícil para uma única empresa, cidade ou governo superar este problema sozinho. Os plásticos foram identificados como uma das cadeias de valor mais representativas do modelo linear atual, trazendo funcionalidade indiscutível para uma variedade de aplicações, mas também acarretando perdas econômicas significativas e severas externalidades, segundo o relatório The New Plastics Economy: Repensando o futuro dos plásticos, lançado na Reunião Anual do Fórum Econômico Mundial de 2016 em Davos-Klosters.

Pela primeira vez foram analisados os fluxos globais dos plásticos e esta visão estabeleceu um novo sistema, mais eficaz, guiado por princípios de economia circular, e apto para o longo prazo. A abordagem excepcionalmente colaborativa, constrói pontes ao longo das cadeias de valor, sectores privado e público para iniciar uma verdadeira mudança do sistema. Este novo relatório mostra que estamos agora firmemente no estágio de ação. A iniciativa solidificou os seus cinco pilares - diálogo, harmonização, inovação, análise e divulgação.

Dentro destas prerrogativas algumas campanhas estão surgindo com a proposta de unir vários setores através da atuação junto ao consumidor em parceria com o governo, iniciativa privada e terceiro setor. Foi lançada na Escócia em janeiro de 2019, a campanha Cup Movement ${ }^{15}$, está sendo implantada pela Keep Scotland Beautifull, ${ }^{16}$ está acontecendo em Glasgow, e é uma resposta à crescente preocupação do público escocês com impacto ambiental de itens de uso único.

Em toda a Escócia são consumidos quase 500 milhões de copos descartáveis ao ano, com uma estimativa de 95 milhões de copos descartáveis sendo usados na grande Glasgow e apenas

\footnotetext{
${ }^{14}$ Disponível em https:/empresaverde.blogspot.com/search?q=caro\%C3\%A7o+de+abacate

${ }^{15}$ Cup Movement - Campanha realizada pela Keep Scotland Beautiful- para maiores informações

https://Keepscotlandbeautiful.org/cups/

${ }^{16}$ Keep Scotland Beautiful é uma organização sem fins lucrativos, especialista em gerenciar campanhas ambientais, que visa educar, inspirar e capacitar as pessoas a mudar seus comportamentos em relação ao lixo, reciclagem e reutilização.
} 
$4 \%$ destinados a reciclagem, o movimento busca transformar a infraestrutura de reciclagem e incentivar as pessoas a adotarem comportamentos mais sustentáveis. A ação consiste em interligar pontos de coleta, facilmente identificáveis, por toda a cidade com a parceria de colaboradores de todos os tamanhos e tipos. Os pontos de coleta são equipados com lixeiras especiais, essas lixeiras além de facilitar a separação do material com informações e formato adequado a cada parte do copo de café, elas também são feitas de material reciclado.

\section{Figura 5 - Coletores de copos de café}

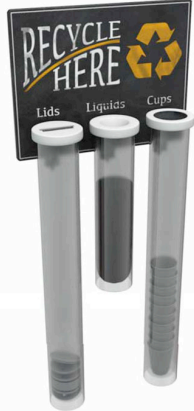

Fonte: Simply Cups 2019

Depois dos copos serem separados adequadamente são coletados e seguem para um centro de reciclagem. Este centro de reciclagem é especial, capaz de reciclar os copos de papel com a camada interna de polietileno. A maioria das empresas de reciclagem de papel é incapaz de fazer esta separação, o que torna os copos de papel praticamente não recicláveis, e isso significa que os copos acabam no lixo comum. Os participantes do Cup Movement recebem desconto neste serviço, que acaba sendo mais econômico do que a coleta normal e ainda melhoram as credenciais ambientais.

Dois dos mais importantes operadores de varejo da Escócia e de Glasgow estão apoiando a ação, o Glasgow Fort e a Buchanan Galleries, entre outros, oferecendo como opção de consumo de copos, os recicláveis ou reutilizáveis, e direcionando milhares de consumidores a fazer escolhas mais sustentáveis. A iniciativa reúne as partes interessadas para interagir com o público. É uma grande iniciativa em busca da redução de copos descartáveis despejados em aterros sanitários ou no lixo, pretendem reciclar copos tanto quanto possível. Se for bem sucedida o modelo poderá ser replicado.

\section{Conclusão}

Quando pensamos em novas opções de materiais para substituir o plástico não estamos respondendo ou resolvendo o problema da descartabilidade. Essa transformação depende de muitos fatores, depende sim de um material que possa realmente ser descartado e que desapareça na mesma velocidade com que é produzido. Para que isso aconteça é necessário que o descarte seja adequado, afinal até o mais orgânico dos materiais, como uma casca de fruta, deve ser corretamente descartado, por isso a informação e a organização de como devemos lidar com o nosso lixo é tão importante. A coleta, a destinação do lixo e a reciclagem devem ser cuidadosamente repensada. Outra parcela essencial é a criação de leis voltadas para adequação dos produtos que usem insumos que permitam uma composição mais orgânica, assim como a proibição do uso de plástico em produtos descartáveis.

Outro ponto que merece atenção é a necessidade de iniciativas regulatórias mais eficientes quanto a responsabilidade do uso do plástico, isso faz com que o seu valor de mercado não seja real pois o dano e os respectivos custos e injurias não estão computados no seu preço. A organização para que este material seja devidamente reciclado necessita de muito investimento. 
Muitos materiais estão sendo pesquisados como bioplásticos, utensílios comestíveis e uma infinidade de possíveis soluções em busca de um material que possa realmente ser descartado, tornando-se uma alternativa ecoeficiente para a substituição do plástico. É possível para a indústria contribuir com a restauração dos ecossistemas, sem gerar passivos sócio ambientais.

Só a reciclagem não resolve a questão do o uso inapropriado do plástico em utensílios descartáveis. Se no caso da Escócia, acima apresentado, um país com pouco mais de cinco milhões de habitantes, com um consumo de 95 milhões de copos descartáveis ao ano e recicla apenas 4\%, fica claro que é necessário uma cadeia de ações para lidar com essa questão, e que a reciclagem embora tenha potencial e gere recursos, é apenas uma parte integrante desta cadeia. Para Alier (1998) a "rota para se encontrar uma sociedade ecológica não passa somente pelas políticas de controle e regulamentação nas ofertas de bens e serviços, mas também pela alteração dos padrões de consumo. A sociedade tem papel fundamental na busca de informações e mudança de padrões, além de cobrar melhores práticas das empresas, governo e instituições.

Parece um caminho fértil o desenvolvimento de sistemas mais inclusivos, capaz de estimular a participação da sociedade, governo, iniciativa privada e terceiro setor afim de projetar ações cada vez mais eficazes, criando ciclos de produção regenerativos, em que os resíduos são nutrientes e os produtos geram impactos positivos. Assim como, uma logística adequada em relação aos resíduos sólidos e pesquisas a fim de estabelecer melhores condutas para consumo dos descartáveis e todo o tipo de lixo que geramos. Somados à uma legislação que estenda a responsabilidade da coleta, redução, reuso e gestão dos resíduos plásticos provenientes de suas cadeias de suprimentos parece estender o campo de atuação e responsabilidades aumentando positivamente os resultados para uma existência mais sustentável.

\section{Referências}

ALIER, Joan Martinez. Da Economia Ecológica ao Ecologismo Popular. 2. ed. Blumenau: Furb, 1998. $402 \mathrm{p}$.

ARMSTRONG, James F. et al (Ed.). Philadelphia, Nurses, and the Spanish Influenza Pandemic of 1918. 2001.

<http://www.ibiblio.org/hyperwar/AMH/XX/WWI/flu/philflu/philflu.html>. Acesso em: 09 maio 2019.

BASTOS, Cláudio Rocha. Embalagens Compostáveis: uma estratégia para a redução de impacto ambiental. 2016. 93 f. Dissertação (Mestrado) - Curso de Metrologia, Metrologia Para Qualidade e Inovação, Pontifícia Universidade Católica do Rio de Janeiro, Rio de Janeiro, 2015. Disponível em: <https://www.maxwell.vrac.puc-rio.br/colecao.php?strSecao=resultado\&nrSeq=25786@1>. Acesso em: 28 maio 2019.

Yarsley V. E.\& Couzens E. G.. 1945Plastics. Middlesex: Penguin Books Limited. Google Scholar

BEULAH, France. Uses for Paper Cups and Containers. New York: American Journal of Nursing, 1942.

BIOFASE, México. 2016. Disponível em : < http://empresaverde.blogspot.com/2016/12/quando-oabacate-gera-valor.html >. Acesso em: 16 de julho 2019.

CREATIVE CARBON SCOTLAND(Scotland). Uses for Paper Cups and Containers. New York: American Journal of Nursing, 1942.

CDC (Estados Unidos) . Centers for Disease Control and Prevention. 1946. Disponível em: < https://www.cdc.gov/vaccines/pubs/pinkbook/index.html> Acesso em: 09 maio 2019.

CUP CAMPAIGNER (Estados Unidos) (Ed.). Spare The Little Children. 1910. Disponível em: 
<https://www.kshs.org/index.php?url=km/items/view/214445>. Acesso em: 09 maio 2019.

DEFRA. Waste strategy for England, p. 127. Norwich, UK: 2007. Disponível em < https://assets.publishing.service.gov.uk/government/uploads/system/uploads/attachment_data/f ile/228536/7086.pdf> Acesso em: 18 de julho 2019.

HOPEWELL, Jefferson; DVORAK, Robert; KOSIOR, Edward. Plastics recycling: challenges and opportunities. Philosophical Transactions Of The Royal Society B: Biological Sciences, [s.I.], v. 364, n. 1526, p.2115-2126, 27 jul. 2009. The Royal Society. http://dx.doi.org/10.1098/rstb.2008.0311.

HUGH MOORE (Estados Unidos) (Org.). Essential in War. 1942. Disponível em: <https://disposableamerica.org/course-projects/a-wholesome-drink/section-vii-bombs-shellstanks-planes-and-paper-cups-and-containers-paper-cups-and-world-war-ii/>. Acesso em: 09 maio 2019.

JUEZ, F. M. Contribuciones para una antropologia del diseño. Barcelona: Gedisa Mexicana, 2002.

KATAMI, Takeo et al. Formation of PCDDs, PCDFs, and Coplanar PCBs from Polyvinyl Chloride during Combustion in an Incinerator. Environmental Science \& Technology, [s.I.], v. 36, n. 6, p.1320-1324, mar. 2002. American Chemical Society (ACS). http://dx.doi.org/10.1021/es0109904.

KEEP SCOTLAND BEAUTIFUL (Escócia). Campanha: Cup Movement Glasgow - 2019. Disponível em: http://www.Keepscotlandbeautiful.org/cups/

KEMPE, Marcis (Ed.). New England Water Supplies - A Brief History: Massachusetts Water Resources $\quad 2006 . \quad$ Duthority. em: <http://www.mwra.state.ma.us/04water/html/historypaper/historypaper-mwrakempe.html\#top>. Acesso em: 09 maio 2019.

LAFAYETTE (Estados Unidos). Lafayette College Libraries. Dixie Cup History. 1995. Disponível em: <http://academicmuseum.lafayette.edu/special/dixie/company.html>. Acesso em: 20 maio 2019.

MACHADO, Anderson Abel de Souza et al. Microplastics as an emerging threat to terrestrial ecosystems. 2017. Disponível em: <https://onlinelibrary.wiley.com/doi/abs/10.1111/gcb.14020>. Acesso em: 19 maio 2019.

MEADOWS, Donella H. et al. Limites do Crescimento: Um relatório para o Projeto do Clube de Roma sobre o dilema da Humanidade. 2. ed. São Paulo: Perspectiva, 1978. 103 f. Disponível em: <https://www.scribd.com/doc/218016244/Limites-Do-Crescimento>. Acesso em: 20 maio 2019.

NEEDHAM, Joseph. Science and Civilization in China: Paper and Printing. 1985. Disponível em: $<$ https://books.google.com.br/books?id=Lx-

9mS6Aa4wC\&pg=PA122\&redir_esc=y\#v=onepage\&q\&f=false>. Acesso em: 20 maio 2019.

PACKARD, Vance. Estratégia do Desperdício. São Paulo: Ibrasa, 2ae ed, 1965.

SONG, J. H., Murphy R. J., Narayan R.\& Davies G. B. H. Biodegradable and compostable alternatives to conventional plastics. 2009. Phil. Trans. R. Soc. B 364, 2127-2139. (doi:10.1098/rstb.2008.0289). Link, Google Scholar

WRAP, Consumer attitudes to biopolymers. Banbury, UK: WRAP, 2007.

WRAP, Biopolymer packaging in UK grocery market, Banbury, UK: WRAP, 2009.

WIT, W.; HAMILTON, A. ; SCHEER, R. ; STAKES T.; ALLAN S. Solucionar a Poluição Plástica: Transparência e Responsabilização. Suíssa: WWF - Fundo Mundial para a Natureza, 2019.

WIT, Wijnand de et al. Solucionar a Poluição plástica: Transparência e Responsabilização. 2019. Dalberg Advisors. Disponível em: <http://promo.wwf.org.br/solucionar-a-poluicao-plasticatransparencia-e-responsabilizacao>. Acesso em: 16 maio 2019. 
World Economic Forum, Ellen MacArthur Foundation and McKinsey \& Company.The New Plastics Economy - Rethinking the future of plastics.2016. Disponível em: < http://www.ellenmacarthurfoundation. org/publications>. Acesso em: 19 de julho 2019. Disponível em: < http://www.ellenmacarthurfoundation. org/publications>. Acesso em: 19 de julho 2019.

YARSLEY,V. E.\& Couzens E. G.. 1945Plastics. Middlesex: Penguin Books Limited. Google Scholar. Disponível em :https://www.google.com/search?q=YARSLEY\%2CV.+E.\%26+Couzens+E.+G..+1945Plastics.+Middle sex\%3A+Penguin+Books+Limited.+Google+Scholar\&rlz=1C5CHFA_enBR843BR845\&oq=YARSLEY\%2 CV.+E.\%26+Couzens+E.+G..+1945Plastics.+Middlesex\%3A+Penguin+Books+Limited.+Google+Schol ar\&aqs=chrome..69i57.1236j0j7\&sourceid=chrome\&ie=UTF-8

LAUDON, Kenneth C.; LAUDON, Jane P. Management information systems: new approaches to organization \& technology. 5 th ed. New Jersey: Prentice Hall, 1998.

MEGGS, Philip B. Type \& Image: The Language of Graphic Design. Van Nostrand Reinhold, New York, 1992.

SIMPLAY CUPS (Reino Unido). Loja: Coletores de copos de café descartáveis. 2019. Disponível em: https://simplycups.co.uk/shop/cup-recycling-bins-bags/

SILVA, J. da. Título do artigo: complemento. Nome da Revista, n.o 0, p. 11-15, set 2006.

SUJEITO, A. Título do tópico. In: Nome do Site, 2005. (http://www.enderecodosite.com.br)

WIT, Wijnand de et al. Solucionar a Poluição plástica: Transparência e Responsabilização. 2019. Dalberg Advisors. Disponível em: <http://promo.wwf.org.br/solucionar-a-poluicao-plasticatransparencia-e-responsabilizacao>. Acesso em: 16 maio 2019. 